\title{
ADSORÇÃO DE METAIS RESIDUAIS DO EFLUENTE DE INDÚSTRIA GRÁFICA EM CLINOPTILOLITA
}

\author{
E. ZANIN $^{1}$, J. SCAPINELLO ${ }^{1}$, M. OLIVEIRA ${ }^{1}$, C.L., RAMBO ${ }^{1}$, FRANSCESCON $^{1}$, F., $^{\text {, }}$ \\ FREITAS $^{1}$, L. J. DAL MAGRO ${ }^{1}$ \\ ${ }^{1}$ Universidade Comunitária da Região de Chapecó, Programa de Pós Graduação em Ciências \\ Ambientais \\ E-mail para contato: jacir@unochapeco.edu.br
}

\begin{abstract}
RESUMO - O objetivo do estudo foi avaliar o uso da zeólita clinoptilolita como adsorvente para remoção de metais pesados em efluente de gráficas. Ensaios de adsorção foram realizados com a clinoptilolita para cobre, cromo e ferro. Constatou-se a presença desses metais no efluente avaliado. Utilizando a clinoptilolita para adsorção do cobre, cromo e ferro, obteve-se remoção de $96,0 \%$, $85,1 \%$ e $95,4 \%$, respectivamente, em $\mathrm{pH}$ 4. A série de seletividade da zeólita seguiu a ordem de $\mathrm{Fe}>\mathrm{Cr}>\mathrm{Cu}$. $\mathrm{O}$ mecanismo de adsorção seguiu o modelo cinético de pseudo-segunda ordem para os três metais. As isotermas mostraram que a adsorção do $\mathrm{Cr}$ e do Fe é do tipo favorável, com melhor ajuste ao modelo de Langmuir, e para o $\mathrm{Cu}$ do tipo desfavorável, com ajuste ao modelo de Freundlich. Dados termodinâmicos mostraram que a natureza do processo de adsorção dos metais é espontânea, e o adsorbato apresenta afinidade com a superfície do adsorvente. Testes de genotoxicidade em Allium cepa confirmaram a eficiência do tratamento.
\end{abstract}

\section{INTRODUÇÃO}

O risco apresentado pelos metais pesados na natureza está associado a sua toxicidade e bioacumulação nos seres vivos (Zagatto, 2006). A contaminação da água é comumente provocada pela atividade antropogênica, sendo as indústrias as principais fontes deste tipo de contaminação. Diversas tintas utilizadas para impressão na indústria gráfica contêm traços de metais pesados e, nas limpezas das máquinas de impressão, boa parte destes compostos são dissolvidos e carregados em seus efluentes (Gomes et. al., 2006).

A busca de soluções e alternativas que causem menores riscos e impactos ambientais envolve efetivamente a aplicação de melhores práticas de gerenciamento. Os tratamentos físico-químicos de coagulação-floculação utilizados atualmente atendem bem a remoção dos metais pesados quando estão em altas concentrações no efluente. Porém, nos efluentes da indústria gráfica, os mesmos estão em baixas concentrações, sendo que este método não atinge os padrões de descarte estabelecidos nas resoluções vigentes (Ferreira, 2001).

Desta forma, o estudo da utilização de filtros a base de zeólitas como meio filtrante adsorvente vem ao encontro da necessidade de retenção destes metais antes do envio ao corpo receptor, diminuindo o impacto ambiental ocorrido pelo despejo destes compostos aos rios (Wang e Peng, 2010). Este estudo visa avaliar o uso da zeólita clinoptilolita como material adsorvente para remoção de metais pesados residuais, provenientes do efluente de indústria gráfica, como alternativa aos tratamentos existentes, com realização de um estudo cinético e 
de equilíbrio dos metais isoladamente, e um estudo termodinâmico do modelo de adsorção dos metais.

\section{METODOLOGIA}

A zeólita escolhida para este estudo é um alumino silicato do tipo clinoptilolita, adsorvente específico na remoção de metais pesados, identificado como WATERCEL ZZ.

$\mathrm{O}$ efluente foi coletado em uma máquina off set, oriundo da lavagem dos roletes de impressão. Para caracterização do efluente foram realizadas análises de $\mathrm{pH}$, temperatura, cor, sólidos totais, sólidos voláteis totais e sólidos suspensos voláteis, de acordo com o Standard Methods for the Examination of Water and Wastewater (APHA/AWWA/WEF, 1995).

A análise dos metais cromo, cobre e ferro foram realizadas pelo método de espectrofotometria de absorção atômica (Model AANALYST 800 AAS - Perkin Elmer Precisely ${ }^{\circledR}$ ). A escolha dos metais para os ensaios de adsorção fez-se levando em consideração as maiores concentrações dos mesmos no efluente bruto em relação ao máximo permitido pela legislação (Resolução 430/2011 e 357/2005 - CONAMA).

As cinéticas de adsorção foram realizadas em $\mathrm{pH} 4$, a $25^{\circ} \mathrm{C}, 120 \mathrm{rpm}$, com $0,5 \mathrm{~g}$ de adsorvente em $100 \mathrm{~mL}$ de solução contendo $10 \mathrm{mg} / \mathrm{L}$ do metal avaliado (individualmente). Os dados termodinâmicos foram obtidos através de ensaios em batelada nas temperaturas de 30 , 40 e $50^{\circ} \mathrm{C}$, com as mesmas condições dos ensaios cinéticos. Todos os ensaios foram realizados em triplicata. As análises da eficiência da adsorção com o efluente foram conduzidas nas condições experimentais ótimas, $\mathrm{pH} 4$, temperatura $25^{\circ} \mathrm{C}$ e tempo de equilíbrio de 360 minutos, utilizando diferentes quantidades de adsorvente em $50 \mathrm{ml}$ de efluente $(0,50 ; 1,50 ; 3,00$ e $10,0 \mathrm{~g})$.

O ensaio de toxicidade consistiu na germinação de sementes de Allium cepa em cada amostra de efluente tratado e água ultrapura como controle negativo por $96 \mathrm{~h}$. Foram avaliadas o número de sementes germinadas e total de aberrações cromossômicas no ciclo mitótico (TCA) (Grant, 1982; Fiskesjö, 1985).

\section{RESULTADOS E DISCUSSÃO}

\subsection{Análises físico-químicas e de metais do efluente da indústria gráfica}

As análises dos parâmetros físico-químicos da amostra de efluente de indústria gráfica,

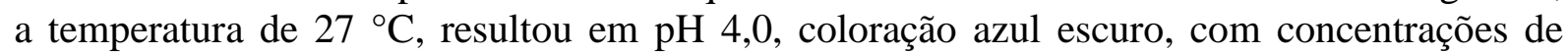
$2264 \mathrm{mg} / \mathrm{L}$ para sólidos totais, $1054 \mathrm{mg} / \mathrm{L}$ para sólidos totais dissolvidos e $1033 \mathrm{mg} / \mathrm{L}$ para sólidos suspensos voláteis. Observa-se através dos resultados que o efluente possui alta concentrações de sólidos em suspensão, provenientes das limpezas dos rolos de impressão que concentram o excesso de corantes na forma sólida, além dos solventes e outras soluções utilizadas para impressão.

Conforme pode ser visualizado na Tabela 1, todos os metais analisados foram encontrados na amostra de efluente coletada, o que evidencia o uso destes metais pesados na composição dos pigmentos utilizados de impressão gráfica. Com relação ao limite máximo de concentração, estipulados na CONAMA 430/2011, todos os metais estão dentro do limite máximo permitido, com o metal cromo muito próximo do limite. Com relação à Resolução 357/2005 do CONAMA, para despejo em rios classe 3, o metal cromo apresentou valores 
acima do limite imposto. O cobre e o ferro estão bastante próximos do limite. Para rios classe 1 e 2, os três metais analisados estão acima do limite máximo permitido pela Resolução $357 / 2005$ do CONAMA. O maior problema dos despejos de metais em águas fluviais é o potencial bioacumulativo que os mesmos possuem diante dos organismos vivos (ESTEVES, 1998).

Tabela 1 - Concentrações de metais no efluente de gráfica

\begin{tabular}{ccccc}
\hline Metal & Concentração (mg/L) & CONAMA 430/11 & CONAMA 357/05 & CONAMA 357/05 $^{3}$ \\
\hline Cobre & $0,1220 \pm 0,004$ & 1,0 & 0,013 & 0,009 \\
Cromo & $0,0935 \pm 0,029$ & $0,1 / 1,0$ & 0,05 & 0,05 \\
Ferro & $4,4125 \pm 0,038$ & 15,0 & 5,0 & 0,3 \\
\hline
\end{tabular}

${ }^{1}$ Limites aceitos para padrões de lançamento de efluentes sanitários e industriais.

${ }^{2}$ Rio Classe $3{ }^{3}$ Rio de Classe 1 e 2

\subsection{Cinética de adsorção}

Os ensaios cinéticos em batelada são realizados com o objetivo de determinar o tempo necessário para se alcançar o equilíbrio entre o adsorbato e o adsorvente, conhecido como equilíbrio de adsorção. Através da Figura 1 - A, verifica-se que em todos os ensaios a remoção dos metais pelo adsorvente foi rápida no início, tornando-se gradativamente mais lenta até alcançar o equilíbrio. Para o cobre o tempo de equilíbrio foi atingido aos $180 \mathrm{~min}$ de ensaio, obtendo-se 96,02 \% de remoção; para o cromo o tempo de equilíbrio foi alcançado aos 300 min com $85,11 \%$ de remoção; e para o ferro o tempo de equilíbrio foi atingido aos 360 min com 95,42 \% de remoção.

O tempo de contato entre o adsorvente e o adsorbato é uma informação importante para o tratamento de efluentes aquosos por adsorção, a remoção rápida do adsorbato e o alcance do equilíbrio em um período curto de tempo indicam que o adsorvente é eficiente (MALL et al., 2006). A forma contínua da curva até a saturação sugere uma cobertura por monocamada dos metais na superfície do adsorvente (Fungaro e Izidoro, 2006).
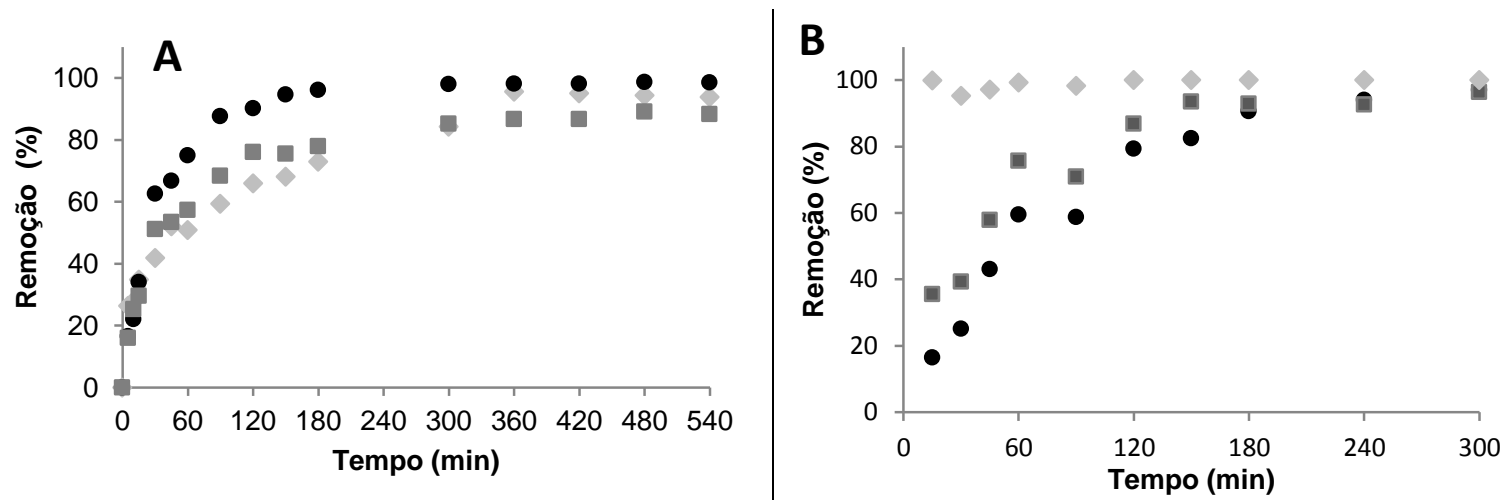

Figura 1 - A: Dados experimentais da cinética de adsorção do cromo, cobre e ferro na concentração inicial de $10 \mathrm{mg} / \mathrm{L}$ a $25^{\circ} \mathrm{C}$ e $120 \mathrm{rpm}$ de agitação, pH inicial 4,0.

B: Porcentagem de remoção na adsorção do ferro, cromo e cobre em uma mistura ternária, na concentração inicial de $3,33 \mathrm{mg} / \mathrm{L}$ de cada metal a $25^{\circ} \mathrm{C}$. $\bullet$ Cobre, $\square$ Cromo, $\diamond$ Ferro. 
Com o objetivo de verificar se a zeólita apresenta preferência em adsorver um metal mais do que outro, realizou-se um experimento cinético com presença dos três metais em iguais concentrações. Observou-se que a zeólita apresentou maior afinidade pelo ferro, seguido do cromo e cobre (Figura 1 - B), o que indica que a zeólita é seletiva para estes metais. Verifica-se também que o ferro foi o único composto que a zeólita adsorveu completamente. A adsorção do cromo e do cobre não foi completa no início, possivelmente devido à maioria dos sítios ativos do adsorvente já estarem ocupados pelo ferro. Verifica-se que o íon ferro e o cromo, que apresentam carga $3^{+}$, apresentaram preferência em serem adsorvidos pela zeólita.

Para avaliar o mecanismo de interação entre o complexo adsorvente-adsorbato, os modelos de Lagergren de pseudo-primeira ordem e pseudo-segunda ordem foram aplicados aos dados experimentais. A partir desses modelos, foram calculados valores da constante de velocidade de adsorção dos modelos (k) e também, a quantidade adsorvida pelo adsorvente no equilíbrio $\left(\mathrm{q}_{\mathrm{e}}\right)$ experimental e teórico (Tabelas 2 e 3). A diferença entre $\mathrm{q}_{\mathrm{e}}$ experimental e $\mathrm{q}_{\mathrm{e}}$ calculado demonstra que o modelo cinético de pseudo-primeira ordem não se ajusta de forma satisfatória aos dados experimentais, resultando em valores de coeficiente de correlação linear abaixo de 0,98 para cromo e ferro.

Tabela 2 - Parâmetros cinéticos do modelo de pseudo-primeira ordem e o valor de qe obtido experimentalmente, com concentração inicial de $10 \mathrm{mg} / \mathrm{L}$ de $\mathrm{Fe}, \mathrm{Cu}$ e $\mathrm{Cr}$.

\begin{tabular}{cccccc}
\hline Metal & Adsorvente & $\mathrm{k}_{1}\left(\mathrm{~min}^{-1}\right)$ & $\mathrm{q}_{\mathrm{e}} \operatorname{Exp}(\mathrm{mg} / \mathrm{g})$ & $\mathrm{q}_{\mathrm{e}}$ teórico $(\mathrm{mg} / \mathrm{g})$ & $\mathrm{R}^{2}$ \\
\hline Cobre & & 0,0238 & 1,845 & 1,669 & 0,9938 \\
Cromo & Clinoptilolita & 0,0134 & 1,661 & 1,261 & 0,9778 \\
Ferro & & 0,0063 & 1,759 & 1,280 & 0,9768 \\
\hline
\end{tabular}

O coeficiente de determinação da reta obtido para o modelo cinético de pseudosegunda ordem aproximou-se mais da unidade para os três metais estudados, quando comparado com o modelo cinético de pseudo-primeira ordem (Tabela 3). Com relação ao desvio entre a quantidade adsorvida calculada e experimental no equilíbrio, este valor também foi menor neste modelo. Isto significa que, a taxa de adsorção é diretamente proporcional ao quadrado da concentração dos metais e, é possível afirmar que o modelo cinético de pseudosegunda ordem apresentou um melhor ajuste dos dados experimentais.

Tabela 3 - Parâmetros cinéticos do modelo de pseudo-segunda ordem e o valor de $\mathrm{q}_{\mathrm{e}}$ obtido experimentalmente, com concentração inicial de $10 \mathrm{mg} / \mathrm{L}$ de $\mathrm{Fe}, \mathrm{Cu}$ e $\mathrm{Cr}$.

\begin{tabular}{ccccccc}
\hline Metal & Adsorvente & $\begin{array}{c}\mathrm{k}_{2} \\
(\mathrm{~g} / \mathrm{mg} \cdot \min )\end{array}$ & $\begin{array}{c}\mathrm{H} \\
(\mathrm{mg} / \mathrm{g} \cdot \mathrm{min})\end{array}$ & $\begin{array}{c}\mathrm{q}_{\mathrm{e}} \text { exp. } \\
(\mathrm{mg} / \mathrm{g})\end{array}$ & $\begin{array}{c}\mathrm{q}_{\mathrm{e}} \text { teórico } \\
(\mathrm{mg} / \mathrm{g})\end{array}$ & $\mathrm{R}^{2}$ \\
\hline Cobre & & 0,0237 & 0,944 & 1,845 & 1,994 & 0,9996 \\
Cromo & Clinoptilolita & 0,0173 & 0,579 & 1,661 & 1,831 & 0,9997 \\
Ferro & & 0,0111 & 0,397 & 1,759 & 1,884 & 0,9943 \\
\hline
\end{tabular}

\subsection{Isotermas de adsorção}

As isotermas de adsorção foram obtidas para cada metal individual (Tabela 4). Os dados experimentais foram ajustados pelos modelos de Langmuir e Freundlich, que são 
frequentemente os mais usados para descrever isotermas de adsorção com aplicações em tratamento de águas e efluentes (FUNGARO et al., 2009).

Tabela 4 - Valores dos parâmetros de equilíbrio das isotermas de Langmuir e Freundlich para os metais cromo, cobre e ferro.

\begin{tabular}{ccccc}
\hline Isoterma & Parâmetro & Cromo $^{1}$ & Cobre $^{2}$ & Ferro $^{1}$ \\
\hline \multirow{5}{*}{ Langmuir } & $\mathrm{q}_{\text {máx }}(\mathrm{mg} / \mathrm{g})$ & 2,5348 & 99,0029 & 1,9149 \\
& $\mathrm{~K}_{\mathrm{L}}(\mathrm{L} / \mathrm{mg})$ & 0,7109 & 0,0364 & 4,1479 \\
& $\mathrm{R}_{\mathrm{L}}$ & 0,1283 & 0,7271 & 0,0256 \\
& $\mathrm{R}^{2}$ & 0,9864 & 0,7896 & 0,9946 \\
\hline \multirow{3}{*}{ Freundlich } & $\mathrm{n}$ & 2,5517 & 0,3730 & 5,2056 \\
& $\mathrm{~K}_{\mathrm{f}}$ & 1,1072 & 5,8468 & 1,4246 \\
& $\mathrm{R}^{2}$ & 0,9274 & 0,9540 & 0,9740 \\
\hline
\end{tabular}

Método de regressão linear; ${ }^{2}$ Método de regressão não-linear

Analisando os resultados, verifica-se que a isoterma do cromo ajustou-se melhor ao modelo de Langmuir $\left(\mathrm{R}^{2}\right.$ : 0,9864). O formato convexo da isoterma (Figura $2-\mathrm{A}$ ) demonstra que a adsorção é favorável (McCabe et al., 2005), e este resultado é confirmado pelo parâmetro de equilíbrio de Langmuir $\mathrm{R}_{\mathrm{L}}=0,1283$, sendo que valores de $\mathrm{R}_{\mathrm{L}}$ entre 0 e 1 condizem a isotermas favoráveis. O melhor ajuste para o modelo de Langmuir assume uma adsorção em monocamada em superfície homogênea.
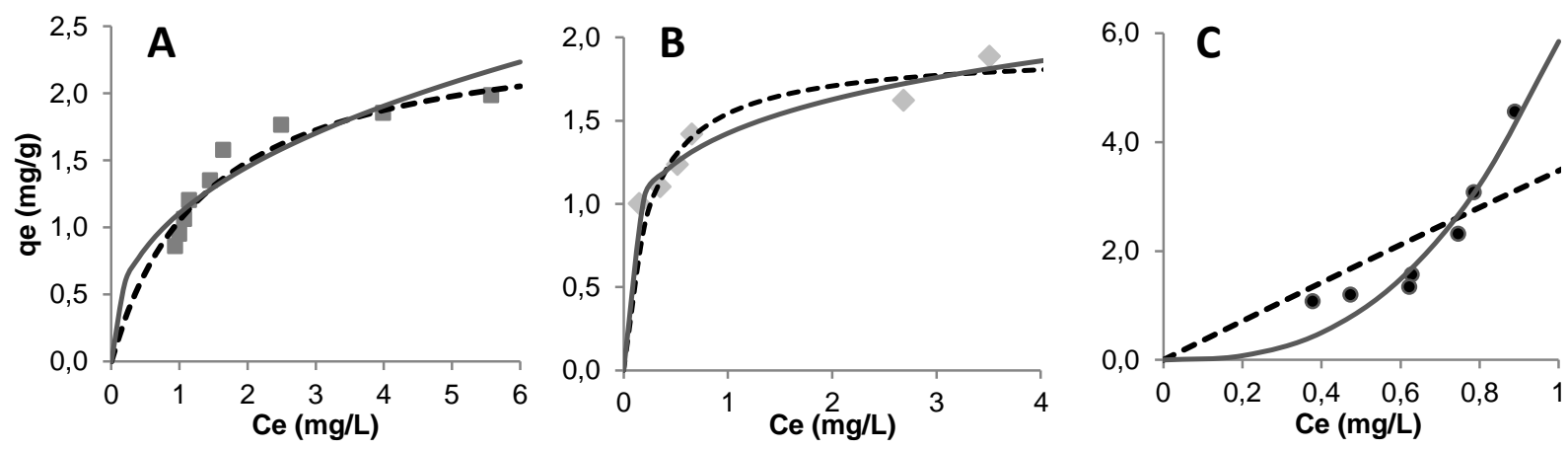

Figura 2 - A: Dados experimentais isoterma de adsorção para o cromo ( $\square$ ). B: Dados experimentais para isoterma de adsorção para o Ferro ( $\diamond$ ). C: Dados experimentais Isoterma de absorção para o Cobre $(\bullet)$. -- Dados ajustados pelos modelos de Langmuir. —Dados ajustados pelos modelos de Freundlich.

Para o ferro, ambos os modelos de isoterma de Langmuir $\left(\mathrm{R}^{2}: 0,9946\right)$ e Freundlich $\left(\mathrm{R}^{2}\right.$ : 0,9740) podem descrever os dados experimentais de adsorção (Figura 2 -B). O formato convexo da isoterma demostra que a adsorção é favorável (McCabe et al., 2005), e este resultado é confirmado pelo parâmetro de equilíbrio de Langmuir $\mathrm{R}_{\mathrm{L}}$ 0,0256 e também pelo parâmetro de Freundlich 1/n 0,1921, no qual valores entre 0,1 e 0,5 indicam processo de adsorção favorável. Porém, como o modelo de Langmuir apresentou um melhor coeficiente de determinação, pode-se dizer que este modelo foi o que apresentou melhor ajuste.

Pela Figura 2 - C é possível observar que os dados experimentais do cobre apresentaram melhor ajuste ao modelo de Freundlich, indicando uma adsorção em superfície heterogênea. 
A forma côncava da curva da isoterma mostra que a adsorção é desfavorável (McCabe et al., $2005)$, evidenciada pelo valor de $1 / \mathrm{n} 2,68$, fora do intervalo de isotermas favoráveis $(0,1<1 / \mathrm{n}$ $<0,5)$. O valor obtido do $\mathrm{q}_{\max }$ do ajuste do modelo de Langmuir não tem significado físico, portanto não é um bom ajuste.

\subsection{Parâmetros termodinâmicos}

Para todos os metais e todas as temperaturas estudadas, os valores negativos de $\Delta \mathrm{G}^{\circ}$ indicam que a natureza do processo de adsorção dos metais é espontânea, mostrando que termodinamicamente há uma redução na energia livre de Gibbs, confirmando a viabilidade do processo de adsorção nas condições avaliadas (Tabela 5).

Tabela 5 - Parâmetros termodinâmicos da adsorção do cobre, cromo e ferro

\begin{tabular}{cccccc}
\hline $\begin{array}{c}\text { Metal } \\
(10 \mathrm{mg} / \mathrm{L})\end{array}$ & $\mathrm{T}\left({ }^{\circ} \mathrm{C}\right)$ & $\mathrm{kc}$ & $\begin{array}{c}\Delta \mathrm{G}^{\circ} \\
(\mathrm{kJ} / \mathrm{mol})\end{array}$ & $\begin{array}{c}\Delta \mathrm{H}^{\circ} \\
(\mathrm{kJ} / \mathrm{mol})\end{array}$ & $\begin{array}{c}\Delta \mathrm{S}^{\circ} \\
(\mathrm{kJ} / \mathrm{mol} . \mathrm{K})\end{array}$ \\
\hline \multirow{3}{*}{ Cobre } & 30 & 28,04 & $-227,16$ & $-27,68$ & 0,46 \\
& 40 & 39,81 & $-334,74$ & $-5,95$ & 0,46 \\
& 50 & 42,73 & $-426,45$ & & \\
Cromo & 30 & 14,21 & $-180,82$ & 41,07 & 0,84 \\
& 40 & 8,44 & $-193,82$ & 50,35 & 1,09 \\
& 50 & 4,64 & $-174,33$ & & 1,41 \\
Ferro & 30 & 331,22 & $-395,411$ & 34,35 & 1,85 \\
& 40 & 511,82 & $-566,75$ & 13,23 & \\
\hline
\end{tabular}

Os valores positivos de $\Delta \mathrm{H}^{\circ}$ para a adsorção de cromo e ferro foram indicativos de que o processo de adsorção é de natureza endotérmica (Tabela 5). Isto sugere que os sistemas têm que retirar energia do ambiente para superar a forças repulsivas e, assim, mover mais próximo da superfície o metal catiônico. Os valores negativos de $\Delta \mathrm{H}^{\circ}$ indicaram natureza exotérmica da adsorção apenas para o metal cobre. Segundo Immich (2006), a variação positiva da entropia padrão indica a afinidade entre o adsorbato e a superfície do adsorvente. Os valores positivos de $\Delta \mathrm{S}^{\circ}$ para todos os metais indicam que ocorre um aumento da desordem na interface sólido/solução durante o processo de adsorção dos metais. Este fato pode ser explicado pela repulsão eletrostática que enfraquece a força de adsorção e aumenta o grau de liberdade das moléculas do metal na superfície do adsorvente.

\subsection{Eficiência de adsorção no efluente bruto e testes de toxicidade}

Após o tempo de equilíbrio de 360 minutos de adsorção, observou-se que em todos os tratamentos ocorreu alta redução dos metais cromo, cobre e ferro no efluente (Tabela 5), com valores abaixo dos limites aceitos pela legislação para liberação de efluentes aos corpos receptores. 
Tabela 5 - Concentração de cobre, cromo e ferro no efluente bruto nos diferentes tratamentos

\begin{tabular}{lccc}
\hline & $\mathrm{Cu}(\mathrm{mg} / \mathrm{L})$ & $\mathrm{Fe}(\mathrm{mg} / \mathrm{L})$ & $\mathrm{Cr}(\mathrm{mg} / \mathrm{L})$ \\
\hline Adsorvente / Efluente Bruto & 0,122 & 4,410 & 0,331 \\
$0,5 \mathrm{~g} / 50 \mathrm{ml}$ & 0,0038 & 1,397 & 0,025 \\
$1,5 \mathrm{~g} / 50 \mathrm{ml}$ & 0,0035 & 1,387 & 0,007 \\
$3,0 \mathrm{~g} / 50 \mathrm{ml}$ & 0,0022 & 1,381 & 0,0011 \\
$10,0 \mathrm{~g} / 50 \mathrm{ml}$ & 0,0013 & 0,49 & 0,000 \\
\hline Res. Conama 357/05 & 0,009 & 0,300 & 0,050 \\
Res. Conama 430/11 & 1,000 & 15,000 & 0,100 \\
\hline Eficiência de adsorção com & 98,93 & 88,89 & 100,00 \\
$10 \mathrm{~g}$ de adsorvente (\%) & & & \\
\hline
\end{tabular}

Para os testes de toxicidade, foram encontradas diferenças significativas em relação ao controle negativo apenas para o efluente bruto. Os tratamentos utilizando zeólita como adsorvente em todas as concentrações testadas não apresentou diferença quanto ao controle negativo (Figura 3 - A). Com relação aos parâmetros genotóxicos, a maioria dos tratamentos avaliados apresentaram efeito citotóxico e genotóxico, porém todos os tratamentos igualaramse ao controle negativo, sendo que somente o tratamento com $10 \mathrm{~g}$ de zeólita diferenciou-se do efluente bruto (Figura 3 - B). Estes resultados mostram claramente que o uso da zeólita clinoptilolita como adsorvente é eficiente como tratamento de efluente de indústria gráfica, tornando-o não tóxico e em condições de liberação ao meio ambiente.
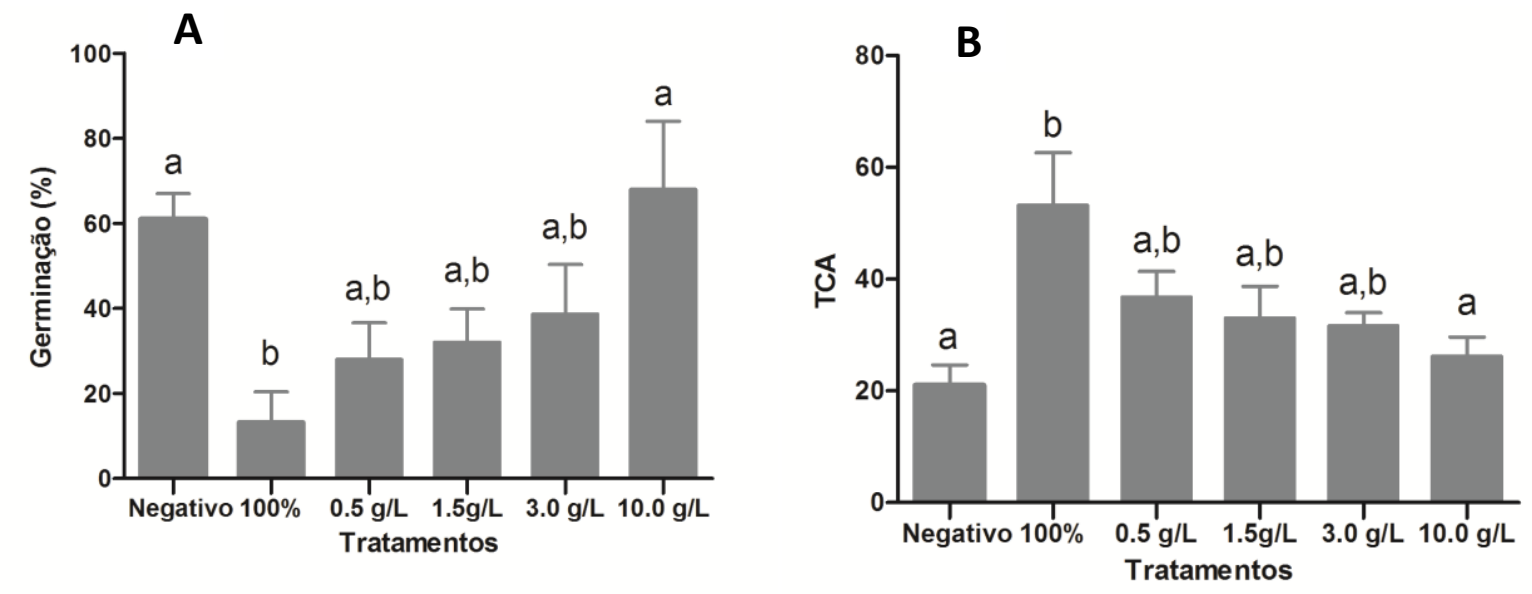

Figura 3 - A: Resultados de germinação. B: TCA em células meristemáticas de Allium cepa após o tratamento com as diferentes concentrações de adsorvente. Letras diferentes indicam diferença estatística $(\mathrm{P} \leq 0,05)$

\section{CONCLUSÕES}

Através de nossos estudos podemos concluir que a clinoptilolita se mostrou como um adsorvente natural eficiente, para adsorver metais pesados de efluentes da industria gráfica, podendo ser utilizada como material alternativo, tendo em vista a sua alta disponibilidade, facilidade de manuseio, baixo custo e seletividade. 


\section{REFERÊNCIAS}

AMERICAN PUBLIC HEALTH ASSOCIATION (APHA); American Water Works Association (AWWA); Water Environmental Federation (WEF). Standard Methods for the Examination of Water and Wastewater. 19 ed. Washington, 1995.

BRASIL. Resolução CONAMA $n^{o}$ 357. Conselho Nacional do Meio Ambiente. Brasília, Diário Oficial da União, 17 de março de 2005.

BRASIL. Resolução CONAMA $n^{\circ}$ 430. Conselho Nacional do Meio Ambiente. Brasília, Diário Oficial da União, 16 de maio de 2011

ESTEVES, F. A. Fundamentos de Limnologia, Rio de Janeiro: Interciência, 1998.

FERREIRA, O. P. Desenvolvimento de materiais porosos bidimensionais, à base de $\mathrm{Al}^{+3}$ e $\mathrm{M}^{2+}$ (Zn, Mg), para uso na remediação de efluentes de indústrias têxteis. 2001. Dissertação (Mestrado) - Universidade Estadual de Campinas, Campinas.

FISKESJÖ, G. The Allium test as a standard in environmental monitoring. Hereditas, v.102, p. 99-112, 1985.

FUNGARO, D. A.; IZIDORO, J. C. Desempenho físico-químico de metais e estruturas de concreto de redes de distribuição de energia: estudo de caso na região de Manaus. Quím. Nova, São Paulo, v. 29, p. 735, 2006.

FUNGARO, D. A.; IZIDORO, J. C, BRUNO, M. Aplicação de material zeolítico sintetizado de cinzas de carvão como adsorvente de poluentes de água. Eclét. Quím., v. 34, 2009.

GOMES, C. Z.; STEGHANHA, R.; SANTOS, J. E. G.; TRINDADE, G. Consciência ambiental: resíduos gerados pelas tintas e solventes em flexografia. XIII SIMPEP, Bauru/SP, nov. 2006.

GRANT, W.F. Chromosome aberration assays in Allium: a report of the U.S. environmental protection agency Gene-Tox program. Mutation Research, v.99, p. 273-291, 1982.

IMMICH, A. P. S. Remoção de corantes de efluentes têxteis utilizando folhas de Azadirachta indica como adsorvente. Dissertação (Mestrado), Programa de Pós Graduação em Engenharia Química - UFSC, 2006.

McCABE W. L.; SMITH. J. C.; HARRIOTT. P. Unit operations of Chemical Engineering. 7. ed. New York: McGraw Hill. 2005.

MALL, I. D.; SRIVASTAVA, V. C.; AGARWAL, N. K. Removal of orange-G and methyl violet by adsorption onto bagasse fly ash-kinetic study and equilibrium isotherm analyses. Dyes and Pig., v. 69, p. 210-223, 2006.

SEPEHR, M. N.; ZARRABI, M.; KAZEMIAN, H.; AMRANE, A.; YAGHMAIAN, K.; GHAFFARI, H. R. Removal of hardness agents, calcium and magnesium, by natural and alkaline modified pumice stones in single and binary systems. Appl. Surf. Sci., v. 274, p. 295305, 2013.

ZAGATTO, P. A.; BERTOLETTI, E. Ecotoxicologia Aquática: Princípios e Aplicações. São Paulo: Rima, 2006.

WANG, S; PENG, Y. Natural zeolites as effective adsorbents in water and wastewater treatment. Chem. Eng. J., v. 156, p 11-24, 2010. 